nightmare, as the thin edge of the wedge, as in the Nazi experience, as a threat to the trust between patients and doctors and as evidenced by the moral dilemma of doctors themselves.

The ethical dimensions of mercykilling are profound and the authors rightly label the still almost taboo subject 'one of the last serious moral issues for modern society to decide on'. It is certainly an idea viewed with abhorrence by many, but the euthanasia movement has grown rapidly in the USA where 40 States now have 'living will' legislation which effectively authorises the maker's family and doctors not to take 'extraordinary' measures to prolong life when death seems inevitable and the illness incurable. In Britain, the proeuthanasia movement has grown steadily under the auspices of the Voluntary Euthanasia Society but it is the Netherlands which has taken the most radical steps in providing a legal framework with strict guidelines for doctors who have to treat patients who have asked for life-preserving treatment to be withheld at a certain point. The Dutch legislation goes further even than withholding treatment. There, a physician who meets strict criteria, can give a lethal injection to a dying person who has requested death and the physician will not be punished.

It seems unlikely that the British medical profession or the public are yet ready to go that far but this book is a valuable contribution to the debate.

WENDY FISHER GORDON Barrister, 27 Burgh Street, London NI

\section{A Time to be Born, a Time to Die}

Rasa Gustaitis and Ernle W D Young, 267 pages, USA, $\$ 18.95$, AddisonWesley, 1986

This book was written by two nonmedical authors, one of whom, Gustaitis, is a professionl journalist and the other a chaplain and senior lecturer in medical ethics in the Stanford University medical school. They were given the free run of the neonatal, intensive-care nursery at Stanford University and had detailed frequent discussions with the medical and nursing staff, as well as with the parents of very small babies. They lived on the premises and absorbed the whole atmosphere of the problems created by, and sometimes solved by neonatal intensive care.
This book should be compulsory reading for all those engaged in, or considering a career in, neonatal medicine. It is well written and full of understanding and feeling for the babies who can express no opinion, for their parents who do not have a much bigger say in the matter and for the doctors who have to make life-anddeath decisions in an atmosphere of American legislation which may compel them to carry out intensive treatment against their consciences and against the interests of the babies.

What they describe with immense sympathy and understanding is the absolute horror of American medicine, which I am afraid is already creeping into our own practice.

They have admiration for the magnificent technology which is increasing almost every day but which runs far ahead of the consideration of what its application means to so many. It may be best to quote verbatim a paragraph which will give the reader a good impression of the substance and tone of the whole book:

'However, hand in hand with this progress run its side-effects, threatening to trip it and send it crashing into a nightmarish domain where, as in George Orwell's 1984, things become the opposite of what they were intended to be. In the intensive care nursery, where the dramas of neonatology unfold, equipment designed to be therapeutic can turn into machinery for torture. Saving life can mean prolonged dying. Babies are "saved" only to be confined to institutions as total care patients, while their families are destroyed by the "rescue". The burden of choice is as great as its potential.'

The book should be on the shelves in every neonatal intensive-care unit and should be frequently read and not just catalogued.

May we be spared the horrors of intensive neonatal care inflicted on American babies!

JOHN LORBER

Emeritus Professor of Paediatrics, University of Sheffield

\section{Brave New People}

D G Davies, 221 pages, Leicester, $£ 4.95$, Inter-Varsity Press, 1984

This book, written by a professor of anatomy who is a devout Christian, has two main aims. One is to survey the main controversial problem areas in medical ethics around the time of the commencement of life: abortion; artificial insemination; ethics of embryo research and experimentation; prenatal diagnosis; genetic engineering; cloning, and in vitro fertilisation. The book provides a useful survey of the moral problems in these areas, ostensibly from a Christian viewpoint. It is an area which receives little attention in the medical-student curriculum although we will soon be in the position of having to make immediate decisions on such dilemmas, whether as physicians or as parents. I thus found this book of great benefit since it opened my eyes to such controversies and provided me with an information base on which to formulate my own opinions.

The book's second aim is to argue for a mechanism whereby the consensus of society on these issues can be obtained and applied. In order that an appropriate decision may be reached Gareth Davies hopes 'that even those who disagree with my stance on various points will look beyond such disagreement to the underlying principles'. This makes an important point: there is a need for patients, and for society at large, to become more involved in medical decision-making, particularly, perhaps, with regard to general principles. There is no escape from the ramifications of biomedical technology and the many issues raised in the book should provoke the reader into reflecting on his or her own ethics and practices. Furthermore the point is made that many people prefer their doctors to make choices for them in areas such as abortion and prenatal screening. I found this rather disconcerting in its implication that doctors have some particular divine right to preside over human life and that they will always arrive at the 'right' answer.

Overall, I enjoyed reading this fascinating book, which deals with issues that are less than comfortable and conveys some of the dilemmas and quandaries facing personnel involved in making decisions about human life around the time of its inception. The text was refreshingly free from the prententious jargon which sometimes disfigures studies of this sort. The only disappointment is that the book was not able to deal with developments in medical ethics over the past couple of years since it was published in 1984. In particular in the field of research on embryos a discussion of the Warnock committee report would have been 